\title{
Los molinos hidráulicos en la Antigüedad
}

\author{
The watermill in the Antiquity \\ Juan Palomo Palomo y María Pilar Fernández Uriel*
}

\begin{abstract}
RESUMEN
La consideración tradicional sobre los molinos hidráulicos en la Antigüedad ha sido que, aunque conocidos, no dejaron entonces de ser una curiosidad; sería en

la Edad Media cuando alcanzaran su verdadero uso y expansión. Sin embargo, el registro arqueológico ha venido a revelar, especialmente en los últimos treinta años, que además de conocidos fueron usados al menos desde el siglo I

d.C. y que estuvieron plenamente difundidos por todo el mundo romano.
\end{abstract}

PALABRAS CLAVE: Molinos hidráulicos; molinos de agua; uso; expansión; Roma; Antigüedad.

\begin{abstract}
Traditionally, watermills have been thought to be completely known in the Antiquity although only as a curiosity, but were thought not to be really used and spread out until the Middle Ages. However, archaeological research, especially in the last 30 years, has shown that watermills were not only known but also used, at least since the first century $A D$, and fully spread out through the Roman world.
\end{abstract}

KEYWORDS:

Watermill; use; spread; Rome; Antiquity.

\section{INTRODUCCIÓN}

Se narra en Ajbar Maymu'a que en el año 743, durante los conflictos internos posteriores a la conquista musulmana de Hispania, huyendo de sus perseguidores el gobernador Abu l-Jattar se refugiaba en el molino de Kulayb, en la margen del río Guadalquivir (López, 2006: 34). Esta temprana referencia de molinos junto a Córdoba hacía preguntarse a Nieto Cumplido si no podrían atribuírseles una ascendencia romano-visigoda (Nieto, 1984: 65). La duda se planteaba ante la consideración generalizada del molino de agua como eminentemente medieval, pues la cita es sólo treinta y dos años posterior a la conquista de la ciudad por Mugith en

* UNED. Pilar Fernández Uriel. Departamento de Historia Antigüa. UNED. Senda del Rey, 7. 28040. Madrid. E-mail: pfuriel@geo.uned.es.

Juan Palomo Palomo. C/ San Miguel, 5. 14440 Villanueva de Córdoba. E-mail: sibulco@ hotmail.com 
el otoño de 711, un periodo de tiempo no demasiado amplio como para introducir tanto el concepto como la tecnología hidráulica. Además, en los territorios peninsulares afectados por la expansión árabe «no se detectan durante los primeros setenta años restos materiales atribuibles a los conquistadores, ni bajo la forma de restos arqueológicos ni de monumentos significativos» (Manzano, 2006: 126)1.

\section{LA PERSPECTIVA TRADICIONAL DE LOS MOLINOS HIDRÁULICOS EN LA ANTIGÜEDAD}

Aunque, en general, es mucho lo que queda por estudiar sobre el molino hidráulico (pues al haberse estudiado desde distintas disciplinas la información ha quedado bastante fragmentada ${ }^{2}$ ), la consideración de que tiene una ascendencia medieval viene de antiguo. Durante mucho tiempo la imagen ${ }^{3}$ que se tuvo de la tecnología hidráulica en la Antigüedad provino del análisis del único recurso empleado para su estudio, las fuentes documentales. Las citas que se hacían en ellas de los molinos hidráulicos variaban considerablemente para cada época: se conocían algunas menciones para el último periodo de la República y comienzos del Imperio romano, pero, sin embargo, no había ninguna para los siglos II d.C. y III d.C., aunque a partir de entonces las referencias se incrementaban notablemente: unas quince para los siglos cuarto y quinto, y cuarenta en los siglos sexto y séptimo. Las conclusiones que se sacaron a partir de estos datos por distintos analistas no variaron sustancialmente desde la publicación en 1788 del segundo volumen de Johann Beckmann Beiträge zur Geschichte der Erfindungen. Algunos molinos fueron descubiertos ocasionalmente desde esa fecha en contextos arqueológicos

\footnotetext{
1 Incluso en «los restos cerámicos (materiales humildes, pero reveladores sobre las gentes que los fabricaron, distribuían y convivían cotidianamente con ellos), la impresión es muy similar. La conquista, entendida como un abrupto suceso, no llega a reflejarse en una primera fase con la nitidez que cabría esperar de unas poblaciones nuevas. No aparecen técnicas novedosas de fabricación cerámica, no existen formas importadas y, en fin, la impresión generalizada es que existe una continuidad en los materiales datables en el siglo vill, que no se ven afectados por las formas que se documentan en Oriente Próximo en este mismo periodo» (Manzano, 2006: 126).

2 «Nuestro conocimiento de la génesis y de la historia temprana del molino de accionamiento hidráulico es tristemente deficiente en muchos puntos. Todavía, en mi opinión, el hecho más enigmático sobre los molinos de agua antiguos es su tratamiento por la investigación moderna. El progreso ha sido lento, y pienso que han sido dos las condiciones generales para esto: la opinión establecida del estancamiento tecnológico en la Antigüedad, y la ausencia de comunicación entre los ingenieros por un lado y los estudiosos de la Antigüedad Clásica por otro... La carencia de comunicación entre ingenieros y humanistas es un problema de gran impacto, afectando al estudio de la tecnología antigua en general. Arqueólogos clásicos y estudiosos de la historia antigua muy raras veces tienen un conocimiento cuidadoso de los asuntos técnicos, mientras que los ingenieros y tecnólogos muestran una carencia correspondiente de conocimientos que conciernen a la Antigüedad en general y lenguas clásicas en particular» (Winkander, 1985: 152).

3 «Durante generaciones hubo un amplio acuerdo general entre los eruditos de que la Antigüedad en general y el Imperio romano en particular fueron periodos de lento progreso tecnológico y aun de estancamiento total. La más obvia, y quizás más embarazosa, excepción a esta regla es el molino de agua, cuya existencia en tiempos romanos no puede ser negada. En cambio, se han hecho grandes esfuerzos para demostrar que no tenían importancia digna de mención hasta el s. IV o V. Esta proposición de base seguramente no ha animado la búsqueda de más pruebas sobre molinos antiguos, ni en la literatura antigua o la epigrafía, ni en publicaciones arqueológicas» (Wikander, 1985: 152).
} 
pertenecientes a la Antigüedad, pero pasaron desapercibidos o no fueron tomados en consideración prácticamente por los estudiosos de la ingeniería hidráulica hasta la Segunda Guerra Mundial. Incluso el famoso artículo de Marc Bloch sobre el "Avènement et conquêtes du moulin à eau» (Bloch, 1935) se basaba fundamentalmente, tanto como lo hacía el libro de Beckmann de finales del XVIII, en las fuentes escritas (Wikander, 1985: 151).

Según Bloch, aunque el mecanismo tecnológico del molino hidráulico fuese conocido al menos desde los comienzos de nuestra era, es a partir de la Edad Media cuando comienza a ser realmente empleado y difundido de un «modo social»: «Invention antique, le moulin à eau est médiéval par l'époque de sa véritable expansion» (Bloch, 1935). La Edad Media habría sido un tiempo de innovación tecnológica y progreso sin par en cualquier período previo de la historia, basado en la diversificación del uso del molino, lo que permitió después una «revolución» económica y la transformación del orden social ${ }^{4}$.

Pero parecía resultar extraño que quienes habían construido el Acueducto de los Milagros o transformado el paisaje de las Médulas hubiesen usado sólo la fuerza humana y animal para la satisfacer la demanda creciente de las concentraciones humanas ${ }^{5}$ y hubiesen despreciado el empleo de la hidráulica. Para explicar esta aparente contradicción, se evocaron varios argumentos. Uno entra dentro de lo que puede definirse como economía keynesiana: se ha argumentado que Vespasiano «se opuso a la utilización de molinos hidráulicos por contribuir al desempleo, lo que creaba fuertes tensiones sociales y económicas" (López, 2006: 28). En realidad, la anécdota la recoge Suetonio en su Vida de los Doce Césares, 10, XVIII: «A un mecánico que se había comprometido a transportar con poco gasto al Capitolio columnas inmensas, Vespasiano le hizo abonar una importante suma por su proyecto, pero aplazó la ejecución, diciendo: Permitid que alimente al pobre pueblo". Mas, como se ha apuntado (Wilson, 2002: 4), esta actitud particular de Vespasiano no tuvo que ser general ${ }^{6}$, y tampoco las características y las necesidades particulares de la plebe de Roma tenían que ser las comunes del Imperio.

El segundo fue la banausis, el menosprecio de los intelectuales griegos y romanos al uso práctico de la ciencia, como parecía colegirse de la opinión de Ar-

4 V. gr.: «Ubicumque voluerit senior, faciat molendinum. Homines ponnat molendinos ubi senior mon posuerit. (El señor levanta molinos donde quiere. Los vasallos levantan molinos donde no los construye el señor)". (Fuero de San Miguel de Escalada, 1173).

5 «Los molinos de sangre tenían una capacidad productiva limitada y empezaban a ser insuficientes para atender la demanda de las importantes concentraciones humanas, ni siquiera con la utilización de una gran cantidad de esclavos o animales de tiro, cuestión que además cada vez resultaba más cara y difícil de mantener. De la magnitud del problema, sus efectos sociales, económicos y sus consecuencias, nos dan idea las crónicas romanas, que cuentan que Calígula en su mandato decretó la requisa de todos los caballos para poder hacer funcionar los molinos" (López, 2006: 28). No fue la filantropía, empero, el rasgo que más destacaron los cronistas de Calígula. La cita proviene de Suetonio (Vida de los Doce Césares, 4, XXXIX): en una de sus excentricidades requisó todos los animales de tiro, incluidos los destinados a la molienda, ocasionando problemas de abastecimiento: «Seducido por el cebo de la ganancia, mandó llevar de Roma todo el mobiliario de la antigua corte y requisó para el transporte de aquellos objetos todos los carruajes de alquiler y todos los caballos de los molineros, de manera que con frecuencia faltó el pan en Roma».

6 Había un molino funcionando en Avenches, Suiza, durante un periodo anterior - ha podido ser datado por dendrocronología en el 57-58 d.C. (Castella, 1994)—, como veremos posteriormente. 
químedes sobre el asunto que recoge Plutarco $0^{7}$ : consideraba que cualquier uso práctico de su investigación científica lo rebajaría, por lo que no dejó ningún tratado sobre su investigación. Pero la misma descripción de Plutarco sobre Arquímedes es la de un sabio excéntrico, no la de un erudito normal; tampoco Ctesio, Filón - Vitrubio reflejan desprecio alguno hacia la tecnología en sus obras (Wilson, 2002: 4).

El tercer argumento para explicar la ausencia de molinos hidráulicos en el Imperio Romano y su difusión a partir de la Alta Edad Media, fue el esclavismo: disponiendo de una abundante y barata mano de obra servil para atender todos los trabajos penosos, los romanos no se habrían molestado en desarrollar una tecnología inútil a su vista; su escasez posterior habría motivado la aparición de los molinos de agua. "Apoyándose en esta comprobación y algunos otros hechos, concluye Georges Comet, evocamos la indiferencia de la Antigüedad para la técnica, su misma negativa; hablamos de bloqueo de las técnicas, de bloqueo mental’ (Belmont, 2006: 19). Así, sólo con la interrupción del Imperio romano, de la abolición de la esclavitud y del triunfo del cristianismo sobre concepciones animistas de la naturaleza, se eliminaron las inhibiciones sobre la explotación de las fuerzas naturales que hicieron madurar las condiciones sociales para la extensión del molino hidráulico (Wilson, 2002: 2).

El molino se habría convertido después de la Antigüedad Tardía en un factor clave en la transformación feudal de la sociedad de la Edad Media europea, donde habría llegado desde Oriente Próximo: «Si bien el molino aparece en Oriente Medio en la Antigüedad, fue en la Edad Media cuando su uso tuvo una difusión masiva, que estaba destinada a cambiar la historia de Occidente. A esta revolución contribuyen diversos factores: aumento demográfico que multiplica las necesidades alimentarias primero, y de producción de bienes de uso cotidiano después, ya que la desaparición de la esclavitud entre los siglos $v$ y $x \mathrm{l}$ hizo necesario hallar nuevas fuerzas productivas para hacer frente a la progresiva escasez de mano de obra, lo que obliga al descubrimiento de técnicas mejores, principalmente el sistema de leva y el de biela-manivela... El desarrollo de los molinos en la Edad Media constituyó un fenómeno europeo original. Ciertamente el molino fue un elemento importante en el mundo asiático, desde China a Siria, mucho antes de la Edad Media y el mundo musulmán lo empleó largamente desde sus orígenes en el siglo VII. Los numerosos ejemplares de la Península lbérica sin duda han inspirado la construcción de molinos en el mundo cristiano, contra los que habría podido batirse Don Quijote ya en la Alta Edad Media. Y con todo, los molinos de la cristiandad no sólo fueron deudores de una presunta transmisión de saber tecnológico de Oriente a

7 Plutarco, Vidas Paralelas, Marcelo, XVII, 4: «En cuanto a Arquímedes, fue tanto su juicio, tan grande su ingenio y tal su riqueza en teoremas, que sobre aquellos objetos que le habían dado el nombre $y$ gloria de una inteligencia sobrehumana no permitió dejar nada escrito; $y$ es que tenía por innoble y ministerial toda ocupación en la mecánica y todo arte aplicado a nuestros usos, y ponía únicamente su deseo de sobresalir en aquellas cosas que llevan consigo lo bello y excelente, sin mezcla de nada servil, diversas y separadas de las demás, pero que hacen que se entable contienda entre la demostración y la materia...» 
Occidente, en tiempos atribuidos a la obra de los cruzados, sino que son fruto del intenso desarrollo del Occidente cristiano entre los siglos XI y XIV...» (Le Goff, 2005).

Ésta ha sido la opinión generalizada: el molino hidráulico, en definitiva, fue conocido mas «en la Antigüedad, no pasaba de ser una curiosidad» (Le Goff, 2005: 104), y no tuvo uso en ese periodo, hasta que las nuevas circunstancias estructurales de la Edad Media favorecieron su implantación, difusión y diversificación.

Veamos a continuación las distintas fuentes de las que disponemos para su estudio durante el periodo que nos ocupa, cómo se han ido ampliando de modo considerable (especialmente las arqueológicas en los últimos treinta años) y cómo, por tanto, esa percepción varía a tenor de las nuevas evidencias de las que se disponen.

\section{FUENTES ESCRITAS SOBRE MOLINOS HIDRÁULICOS EN LA ANTIGÜEDAD Y ALTA EDAD MEDIA}

\subsection{Textos}

Filón de Bizancio podría haber descrito por primera vez un molino de agua, lo que supondría que su invención habría podido ocurrir hacia mediados del siglo III a.C. en el mundo helenístico (Lewis, 1997).

Estrabón ${ }^{8}$ cita un molino accionado por la fuerza hidráulica en el palacio del rey del Ponto Mitrídates VI (120-63 a. c.) en Cabeira (actual Niksar, Turquía).

Antipater de Tesalónica ${ }^{9}$ (c. 20 a.C.-10 d.C.) cantaba alabanzas a los molinos de agua que sustituían los pesados trabajos de molienda diaria realizados, generalmente, por las mujeres al alba, librándolas de tal carga ${ }^{10}$.

El mecanismo de la rueda hidráulica vertical es descrito por el arquitecto, escritor e ingeniero romano Vitrubio ${ }^{11}$ c. $40-10$ a.C.

${ }^{8}$ Estrabón, Geografía, XII, 3, 30: «En de tois Kabeirois ta basileia Mithridatou kateskeuasto kai ho hudraletês kai ta zôgreia kai hai plêsion thêrai kai ta metalla».

9 Antipater de Tesalónica, Anthologia Graeca, IX, 418: «Dejad de moler, oh mujeres que trabajáis en el molino; seguid durmiendo, aunque el canto de los gallos anuncie el nuevo día. Porque Deméter ha ordenado a las Ninfas que lleven a cabo el trabajo de vuestras manos, y ellas, saltando sobre el tope de la rueda, hacen dar vueltas a su eje, el cual, con sus gigantes rayos mueve las pesadas y cóncavas mudas nisirianas. De nuevo probamos los goces de la vida primitiva tomando los productos de Deméter sin trabajar» (citado en Mumford, 1934).

${ }_{10}$ El trabajo diario en los molinos de mano fue una actividad considerada proverbialmente penosa y degradante (Mateo, 24, 41: "Dos mujeres moliendo en un molino, la una será tomada y la otra dejada»), de ahí que el poeta resalte la liberación de esta esclavitud con la energía hidráulica.

11 Marco Vitrubio Polión, De Architectura, X, 5, 2: «Eadem ratione etiam versantur hydraletae, in quibus eadem sunt omnia praeterquam quod in uno capite axis tympanum dentatum est inclusum. id autem ad perpendiculum conlocatum in cultrum versatur cum rota pariter. secundum id tympanum maius $<$ minus > item dentatum planum est conlocatum, quo continetur ita dentes tympani eius quod est in axe inclusum inpellendo dentes tympani plani cogunt fieri molarum circinationem. in qua machine inpendens 
En la segunda mitad del siglo I d.C. Plinio el Viejo comenta que en gran parte de Italia se usaban ruedas movidas por el agua ${ }^{12}$.

Desde Plinio hay un vacío en las fuentes literarias para los siglos segundo y tercero (aunque se conocen algunas inscripciones), pero a partir de la segunda mitad del siglo Iv d.C. las citas comienzan a abundar. Amiano Marcelino ${ }^{13}(18,8,11)$, en los antecedentes del sitio del rey sasánida Sapor a la ciudad de Amida (Diyarbakir, Turquía) en el 359 d.C. comenta la existencia de molinos construidos aprovechando la abrupta pendiente de una colina (Wilson, 2001b).

El poeta Ausonio ${ }^{14}$ (c. 370 ) evoca los molinos de grano y las sierras ${ }^{15}$ accionadas por la corriente situados en algunos afluentes del río Mosela.

Libanios ${ }^{16}$ nos informa de que los panaderos de Antioquía debían pagar un canon por la utilización de los molinos de agua (c. 387).

Cuando Símaco argumentaba que al suprimir la prerrogativa de las vírgenes vestales se había producido una pública hambruna, el hispano Prudencio ${ }^{17}$ (c. 404) argumentaba que los frutos de las provincias seguían alimentando a la plebe, que continuaban los repartos de alimentos en el Circo y que los molinos del Janículo no paraban de moler, de donde se infiere su existencia («¿Quién viene hambriento a los espectáculos del circo? ¿Qué barrio soporta los rigores del ayuno por estar vacías las gradas o qué muela del Janículo descansa en silencio?»).

San Juan Casiano ${ }^{18}$ (c. 360 - c. 430-435) escribía que la meditación de las Sagradas Escrituras es una actividad del corazón que podía, por su impetuosidad,

infundibulum subministrat molis frumentum et eadem versatione subigitur farina». («El movimiento de los molinos de agua se basa en los mismos principios, excepto en que llevan un tambor dentado en un extremo del eje. El tambor está colocado verticalmente y gira al mismo tiempo que la rueda. Junto a este tambor se halla un segundo tambor mayor, colocado horizontalmente a lo largo del eje, al empujar los dientes del tambor horizontal provocan el movimiento circular de las muelas. Si colgamos una tolva en esta máquina, suministrará trigo a las muelas, y gracias a este mismo movimiento giratorio, obtendremos harina».)

${ }_{12}$ Cayo Plinio Segundo, Naturalis Historia, XVIII, 23, 97: «Maior pars Italiae nudo utitur pilo, rotis etiam, quas aqua verset, obiter et mola».

${ }_{13}$ Amiano Marcelino, XVIII, 8, 11: "Quem scissis collibus molinae ad calles artatas aedificatae densius constringebant» (Wilson, 2001b).

${ }_{14}$ Décimo Magno Ausonio, Mosella, 361-364: «nobilibus Celbis celebratus piscibus, ille praecipiti torquens cerealia saxa rotatu stridentesque trahens per leuia marmora serras audit perpetuos ripa ex utraque tumultus".

${ }_{15}$ Aunque la transformación del movimiento rotario continuo en movimiento alterno se consideró una innovación de la Edad Media, en los siglos XII y XIII (Le Goff, 2005: 104), hay otros testimonios además del de Ausonio sobre el empleo de la energía hidráulica para un fin distinto de la molienda o el triturado anteriores a la plena Edad Media: San Gregorio de Nisa (In Ecclesiasten, 3), hacia el 370-390 d.C. se refiere a la gente que sierra el mármol con el hierro y el agua; dentro del Santuario de Artemisa en Jerash, en una fase del siglo vi d.C., se ha identificado una serrería accionada por agua para cortar piedras de mármol en losas (J. Seigne, 2002: 36-37). «Este descubrimiento es de particular interés porque la inversión en la mecanización para serrar chapas subraya la escala del expolio del material del edificio clásico abandonado en el último período de la Antigüedad; al lado de los restos del hoyo de la rueda fueron encontrados dos fustes de columna" (Wilson, 2002: 16).

16 Libanios, Orationes, IV, 29.

17 Aurelio Prudencio Clemente, Contra Symmachum, II, 948-50: «Quis venit esuriens magni ad spectacula circi, quae regio grandibus vacuis ieiunia dira sustinet, aut quae laniculi mola muta quiescit?».

${ }_{18}$ San Juan Casiano, Collationes patrum in Scithico eremo commorantium, 1, 18. 
compararse con las muelas que no pueden pararse forzadas por el impulso del agua.

La primera mención del agua como fuerza motriz por parte de un agrónomo latino se encuentra en la obra de Paladio ${ }^{19}$, c. siglo v, que recomienda instalar molinos de agua en las villae donde se disponga de abundante agua para economizar mano de obra.

Magno Aurelio Casiodoro ${ }^{20}$, como Quaestor sacri palatii (506-511), recogía el comentario de que el agua de los acueductos de Roma estaba siendo desviada para hacer girar molinos y regar jardines.

Procopio de Cesárea ${ }^{21}$ amplia la información sobre los molinos del monte Janículo en Roma que nombraba Prudencio a tenor del asedio de Roma por los godos en el 537. Cuenta en su Guerra Gótica que todos los molinos de la ciudad habían sido construidos de antiguo en la colina del Janículo, en la otra margen del Tíber, donde eran abastecidos por el agua de los acueductos que llegaba hasta su cresta y se precipitaba con fuerza por la inclinación de la pendiente. Tanto para evitar que los enemigos pudiesen acercarse a la ciudad por esa zona como para proteger los molinos, el Janículo fue rodeado por el muro de Aureliano. Pero el rey Vitiges cortó los acueductos, paralizando la producción de harina. Los romanos, ante la falta de abastecimiento por el asedio, carecían de animales suficientes para suplir su carencia, pero el general Belisario resolvió la situación de otro modo: unió las dos orillas del río con unas cuerdas junto al Pons Aurelius, y tensándolas amarró a ellas varios barcos unidos entre sí donde la corriente fluía con más fuerza. Entre ellos instaló las ruedas hidráulicas, que eran movidas por el Tíber, pudiendo así fabricar la harina necesaria.

El obispo de Aventicum, Marius Aventicensis ${ }^{22}$, señalaba la presencia de molinos en Ginebra hacia el 563.

Gregorio de Tours hace una descripción de Dijon hacia el 580 con molinos junto a sus murallas movidos por un impetuoso torrente ${ }^{23}$.

También santo y obispo, Isidoro de Sevilla ${ }^{24}$ (c. 627-630) no hace mención a molinos de agua, pero sí a ruedas que elevan agua de los ríos, recogiendo un verso de

19 Paladio Rutilio Tauro Emiliano, Opus agriculturae I, 41: «Si aquae copia est, fusoria balnearum debent pistrina suscipere, ut ibi formatis aquariis molis sine animalium uel hominum labore frumenta frangantur» («Si hay abundancia de agua en la instalación de los baños, deben aprovecharla también los molinos para que en ellos, con muelas hidráulicas, puedan molerse los cereales sin el servicio de animales o esclavos"). Poco se sabe sobre el autor. Su obra se convirtió en el único manual al uso de Agricultura desde la temprana Edad Media. Se ha supuesto que lo escribió en el siglo v, aunque un término ante quem seguro lo constituye De institutione divinarum litterarum — c. 540 — de Casiodoro, donde cita a Paladio (Moure, 1990: 135).

20 Magno Aurelio Casiodoro, Variae, III, 31, 2.

21 Procopio de Cesárea, De Bello Gotico, I, 19.

22 Marius Aventicensis, Chronincon.

${ }^{23}$ Gregorio de Tours, Historia Francorum, III, 19: «Al sur, corre el río Ouche, abundante en peces. Por el lado norte penetra otro riachuelo que atraviesa la ciudad, a la par que rodea toda su muralla; a su salida, ante una de las puertas hace girar molinos con prodigiosa velocidad» (citado en Ladero, 2004: 103).

24 Isidoro de Sevilla, Etymologiae, XX, 15, 1: «De instrumentis hortorum. Rota dicta quod quasi ruat: est enim machina de qua e flumine aqua extrahitur. Lucretius ( $V, 517)$ : In fluvio versare rotas atque austra videmus.» 
Lucrecio ${ }^{25}$, poeta latino de la primera mitad del siglo I a.C., sobre esta misma cuestión.

\subsection{Fuentes jurídicas}

En las disposiciones legislativas, en el Editum de Pretiis Maximis (Edicto de Precios Máximos) de Diocleciano (301) sólo consta el valor de las muelas para molinos de sangre o hidráulicos, no la estructura del molino ni el trabajo asociado (XV, 52-55): molino de caballo, 1.500 denarios; molino de asno, 1.250 denarios; molino hidráulico, 2.000 denarios; molino de mano, 250 denarios.

Los molinos de agua son aludidos en una compilación de leyes irlandesas del siglo v (Mumford, 1935). Observa Wikander que los códigos legales germanos, irlandeses o bizantinos muestran más interés que las leyes romanas por los molinos hidráulicos, dando protección a sus partes esenciales, al molinero, caminos 0 cauces de agua. Son citados, v. gr., en la Ley Sálica ${ }^{26}$ (Pactus legis Salicae, XXII) de Clodoveo (comienzos del siglo vi); en el Fuero Juzgo o Liber ludiciorum de los visigodos ${ }^{27}$ (654), en el Pactus Alamannorum, frag. V 14, o en el Edictus (149-151) del longobardo Rotario ${ }^{28}$ (643) (Wikander, 2000).

\subsection{Epigrafía}

Hay constancia epigráfica durante la Antigüedad de menciones a molinos y molineros. Relacionados con los molinos del Janículo, Claudius lulius Ecclesius Dynamius, praefectus urbi de Roma, 475/488 (Wilson, 2002: 13), emitió un decreto (CIL VI. 1711) de fraudibus molendinariorum ${ }^{29}$. En Beroea (Macedonia) un decreto

25 Tito Lucrecio Caro, De Rerum Natura, V, 517: «Ut fluvios versare rotas atque austra videmus».

26 Pactus Legis Salicae, XXII, «De furtis in molino commissis: Si quis ingenuus homo in molino anona aliena furaverit et ei fuerit adprobatum, ipso molinario DC dinarios qui faciunt solidos XV solvet. Ei vero cuius anona est alius XV solvatur. Si ferramento ibidem furaverit, solidos XLV culpabilis iudicetur. Si quis sclusam de farinario ruperit, solidos XV culpabilis iudicetur».

27 Liber ludiciorum, Libro VII, Título II, Ley XII «De los que furtan los fierros ó las otras cosas del molino": "Si algun ombre furta fierros de molino, ó otro engeno, entregue lo que tomó, é demas peche por el furto quanto deve pechar quien furta otras cosas, é demas reciba C. azotes». Libro VIII, Título IV, Ley $\mathrm{XXX}$ «De los que crebantan molinos o pesqueras»: «Si algun omme crebantar molinos ó las pesqueras, todo quanto crebantó refágalo fasta treinta dias, é demas peche veinte sueldos. E si fasta treinta dias no lo ficiere, peche otros veinte sueldos, é demas reciba $C$. azotes. E otrosí decimos de los que crebantan los estancos del agua: si es siervo refaga lo que desfizo, é demas reciba $C$. azotes».

28 Edictus Rothari: «149 De molino incenso. Si quis molinum alterius asto incenderit, id est volumtariae, in treblum eum restituat sub stimationem rei cum omnia, quae intus cremata sunt. 150 De molino capellato. Si quis molinum alterius cappelaverit aut sclusa ruperit sine auctoritatem iudicis, conponat solidos duodicem illi, cuius molinus esse invenitur. Et si iudicem interpellaverit, et iudex dilataverit ipsa causa deliberare, aut licentiam dederit averse parti ipsum molinum evertendi, conponat solidos $X X$ in palatio regis, districtus ab stolesazo. 151 «Si quis molinum in terram alienam aedificaverit et suum probare non potuerit, amittat molinum et omnem operam suam, et ille habeat, cuius terram aut ripam esse invenitur; quia omnes scire debent, quod suum, non alienum est».

29 Véase también: http://penelope.uchicago.edu/Thayer/E/Gazetteer/Places/Europe/Italy/Lazio/ Roma/Rome/_Texts/PLATOP*/Molinae.html 
del II d.C. hace referencia a los ingresos procedentes de los molinos de agua (Gounaropoulou y Hatzopoulos, 1998). Hacia el 200 d.C. existía en Hierápolis (Frigia), un gremio de molineros de agua (Pleket, 1988). La también ciudad frigia de Orkistos solicitó a Constantino el estatus de civitas autónoma; el rescripto imperial de 329-331 de concesión de la petición citaba entre otras cosas una serie de molinos en una corriente próxima (Chastagnol, 1981). De Sardes es la inscripción funeraria de Euchromius (siglos IV-v), constructor de molinos hidráulicos (Buckler y Robinson, 1932).

\section{LA AMPLIACIÓN DE LAS FUENTES DE ESTUDIO: EL ENFOQUE ARQUEOLÓGICO}

Cuando en el estudio de los molinos de agua a las fuentes escritas se agregan las procedentes de la Arqueología, el estereotipo nacido al menos en el siglo XVIII se modifica considerablemente. En la década de los treinta del pasado siglo se publican los primeros trabajos aceptables con la constancia de molinos hidráulicos durante la Antigüedad en Grecia (Parsons, 1936), Italia (Jacono, 1938) o Francia (Benoit, 1940); mas el progreso fue lento, quizá debido a la opinión generalizada establecida sobre el estancamiento tecnológico en esa época; a la dispersión de la información en muy distintas publicaciones; y a que la mayor parte de los eruditos parecían más interesados en acentuar la escasez de tales hallazgos que en la tentativa de encontrar otros que incrementasen el número (Wikander, 1985: 152-152).

A mediados de la década de los 80 del pasado siglo aparecieron unas publicaciones (Wikander, 1984; Wikander: 1985) que venían a modificar la idea comúnmente aceptada de que no sería antes de la temprana Edad Media cuando el empleo del molino de agua se hiciese común (Fig. 1).

\section{Evidence for ancient water-mills (Wikander 1984)}

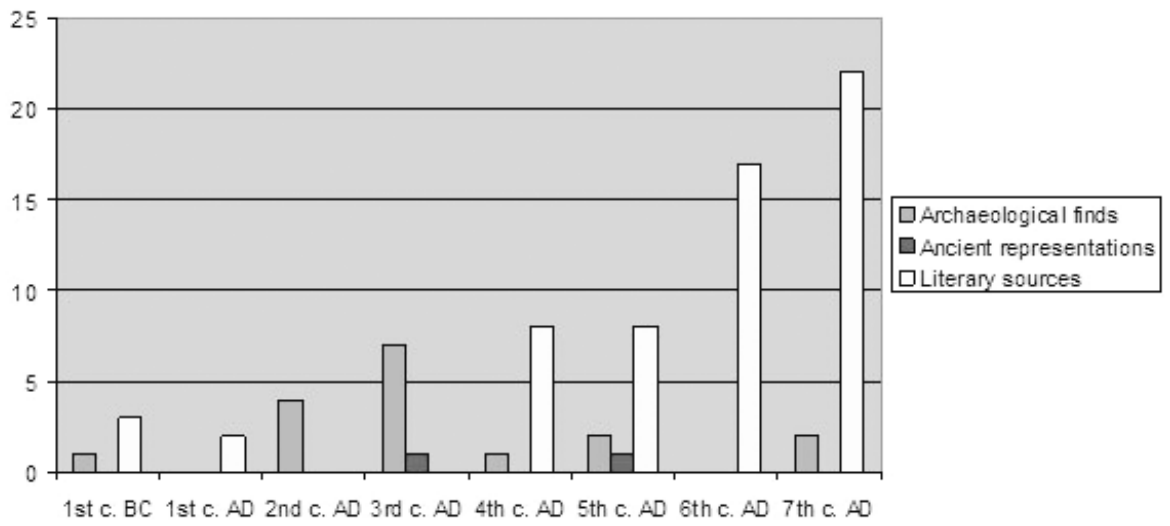

(Fuente: Wilson, 2007: 1).

Fig. 1. Molinos hidráulicos conocidos en 1984. 
La mayor parte del material arqueológico conocido en la década de los 80 del pasado siglo sobre molinos de accionamiento hidráulico correspondía a los siglos II d.C. y III d.C., época de la que no se conocían fuentes escritas que se refirieran a ellos; al contrario, de cuando más constancia documental existía, siglos vi d.C. y vII d.C., apenas si había un par de casos en el registro arqueológico conocido. Ante esta discordancia, Wikander consideró que la información que se encuentra sobre los molinos hidráulicos en las fuentes escritas está en función de la naturaleza y de la supervivencia de dichas fuentes. Del periodo grecorromano se conserva sobre todo poesía (épica, didáctica, elegíaca), filosofía, narraciones históricas - géneros que presumiblemente no dedican mucho tiempo a tratar de molinos hidráulicos $u$ otros objetos de la vida cotidiana-; la mayor parte de las citas provienen de textos científicos, técnicos o enciclopédicos, que son relativamente raros. El aumento de referencias a molinos de agua a partir del siglo iv d.C. coincide con la introducción de nuevos géneros (códigos legales, cartas monásticas), en los que es más probable referirse a tales dispositivos mundanos (Wikander, 1984).

A partir de aquí pueden sacarse dos conclusiones: en primer lugar, las fuentes documentales no bastan por sí solas para ser un baremo fiable sobre la frecuencia del empleo de la fuerza hidráulica en el tiempo; segunda, si la mayor parte de documentos referentes a molinos de agua se dan en la temprana Edad Media, cuando el registro arqueológico de esta época es muy escaso, quiere decirse que el registro arqueológico identificado sólo debe representar una pequeña parte del total original (Wilson, 2007: 1).

En los algo más de veinte años transcurridos desde la publicación de Wikander, si bien apenas se ha conocido alguna fuente escrita más (Lewis, 1997; Wilson, 2001b) el número de molinos de agua descubiertos por intervenciones arqueológicas ha aumentado considerablemente (Fig. 2).

\section{Evidence for ancient water-mills}

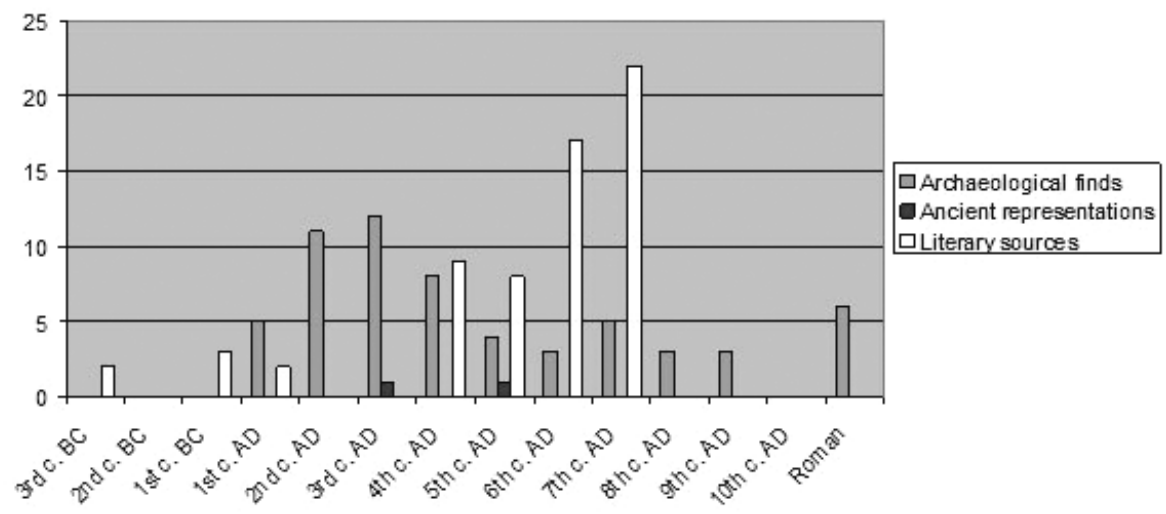

(Fuente: Wilson, 2007: 2)

Fig. 2. Molinos hidráulicos conocidos en 2007. 
Pero, al igual que se valoró el tipo y la cantidad de fuentes textuales relacionadas con los molinos que han llegado hasta nosotros, debe de hacerse con el material arqueológico. Los molinos son vulnerables a la erosión por el cambio del cauce, lo que aumenta la probabilidad de localizarlos en los sitios más antiguos, o lo que es lo mismo, que la supervivencia de lugares romanos sea relativamente mayor que la supervivencia de sitios medievales. También la propensión de los romanos al uso de un material resistente como la piedra en los molinos de Barbegal apuntaría a una identificación proporcionalmente mayor de molinos romanos que los de época altomedieval. Los romanos, sin embargo, emplearon asimismo la madera en Avenches o Lösnich, y los molinos también pueden ser identificados a partir de las piedras de molino hidráulico. En definitiva, el saldo parece estar equilibrado, y la mayor cantidad que se aprecia en el periodo romano parece ser verdadera y no estar sobre representada en el registro arqueológico; y más si consideramos que los seis incluidos en la columna de la derecha de la figura 2 con el nombre genérico de «romano» también son de los siglos I d.C. al Iv d.C. (Wilson, 2007: 2).

Comparando las figuras 1 y 2 , el pico correspondiente a los siglos II d.C. y III d.C. es en la segunda más acentuado, con evidencias apreciables también para el I d.C. y IV d.C. La subida del VII d.C. se debe principalmente al descubrimiento de molinos de marea en Irlanda (Wikander, 2007: 2). El espacio dedicado a los molinos de agua durante la Antigüedad se va incrementando con la publicación de nuevos hallazgos, inventarios o interpretaciones (Lewis, 1997; Brun y Borréani 1998; Wikander, 2000; Wilson, 2001a; Wilson, 2001b; Wilson, 2002; Leveau, 2006; Wilson 2007); o cuenta con una amplia representación en actos como el Coloquio Internacional Le Pont du Gard 20-22 septembre 2006, Force hydraulique et machines à eau dans l'Antiquité romaine, donde se presentaron seis comunicaciones referentes a molinos hidráulicos romanos en Israel, Italia y Francia ${ }^{30}$.

Archaeologically known water-mills dated before c. AD 700: rate of increase in information

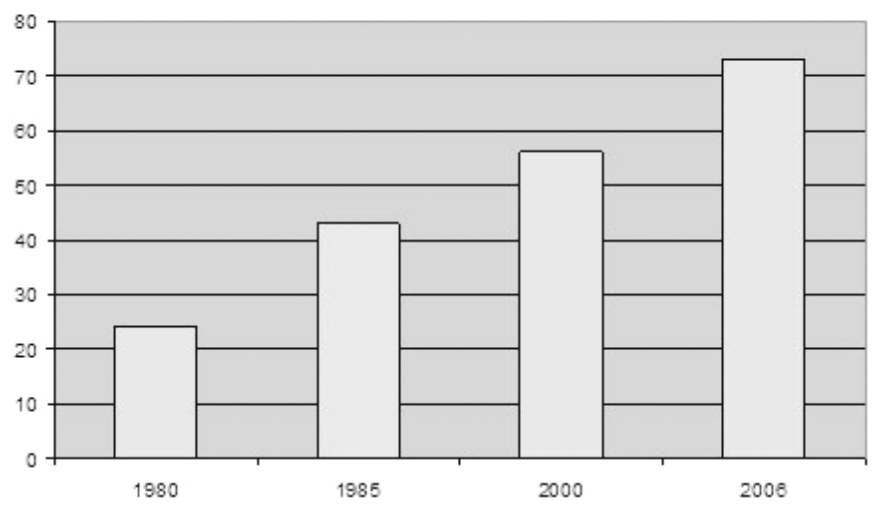

(Fuente: Wilson, 2007, 1)

Fig. 3. Incremento del número de molinos hidráulicos conocidos en el registro arqueológico correspondientes a los primeros siete siglos de la era desde 1980 a 2006.

30 http://f.echasseriaud.free.fr/pages/actu/actu04a.ill/actu0406/pontgard.pdf. 
En la actualidad conocemos molinos por todas partes del mundo romano. Sin pretender hacer un inventario exhaustivo de los mismos, veamos su distribución:

En el Próximo Oriente, además de los ya citados en fuentes literarias y epigráficas (Amida, Antioquía, Cabeira, Orkistos, Sardes e Hierápolis) se conoce un complejo de varias ruedas hidráulicas o molinos de agua en Israel junto al río Crocodilion en Caesarea Marítima (Oleson, 1984); en Cilicia son conocidos en Lama y Kursunlu Selalesi (Ross, 1991); hay un mosaico representando un molino de agua en la ciudad de Constantinopla (Brun y Borréani, 1998). 1936).

En los Balcanes consta un molino de los siglos v-vı en Atenas (Parsons,

Hay complejos de varios molinos en las fértiles tierras del río Medjerda (Túnez), en Chemtou y Testour. Hay constancia de más molinos hidráulicos en el norte de África en Oued Mellah, Oued Bou Ya'koub, Oued Bou Ardoun, Mouzaïa des Mines y quizá también en la antigua Lixus (Wilson, 1995).

En la península italiana la arqueología ha sacado a la luz los molinos del Janículo que nombran Prudencio y Procopio de Cesárea: en 1998 se excavaba en la colina romana del Janículo el Aqua Traiana y el complejo de molinos hidráulicos paralelos al canal principal. Eran conocidos desde 1880, aunque fue a raíz de unas obras en la Via Medici en 1990 cuando comenzó la intervención arqueológica de urgencia. Al menos cinco ruedas se movían impelidas por el acueducto del Aqua Traiana. Podrían haber sido construidos en tiempos de Aureliano (270-275), como parece desprenderse de la referencia de Procopio de que fueron protegidos ex profeso por el Muro de Aureliano; fueron restaurados tras el asedio ostrogodo, y continuaron funcionando al menos hasta la época del papa Gregorio IV (827-844) (Wikander, 1979; Wilson, 2001a). En las termas de Caracalla se construyó un molino al mismo tiempo que las termas en el periodo de 212-235 d.C. En Venafro (Jacono, 1936) apareció una rueda hidráulica, y en Saepinum, en el Samnium, había un molino próximo al foro, en un barrio de tiendas y talleres de artesanos (Wikander, 1985, 159). También en Italia hay que citar Oderzo (Trovò, 1996) y S. Giovanni di Ruoti (Small y Buck, 1994, 94), datado a finales del siglo I d.C.

Francia y Europa Central son los lugares donde se han encontrado más molinos de la Antigüedad. Al este de Arlés, Fernad Benoit descubría en Barbegal un complejo formado por dos hileras con ocho molinos hidráulicos cada una, que aprovechando la pendiente de un barranco se sucedían uno bajo otro como unas escaleras de agua (Benoit, 1940). El conjunto de dieciséis molinos fue protegido por un edificio de $60 \mathrm{~m}$ por $20 \mathrm{~m}$, aunque con una fachada adornada con un pórtico que le daba el aspecto de una fachada de templo (Belmont, 2006: 19). Con un abastecimiento de agua garantizado desde Les Alpilles mediante dos acueductos (Fig. 4) que confluían, tenía una capacidad de producción estimada de 4,5 toneladas de harina diarias (Sellin, 1983), por lo que «los molinos de Barbegal constituían el primer testimonio arqueológico de una utilización industrial de la fuerza hidráulica» (Leveau, 1996: 16). Aunque su descubridor los fechase a finales del siglo III d.C., estudios posteriores dan una datación del complejo bastante anterior, de inicios de la 
segunda década del siglo II d.C. (Leveau, 2006: 9), es decir, en el último periodo de Trajano. Hay más molinos en el territorio de la antigua Galia en Croix de Fenouillé (Buffat, 2006), L'Auribelle Basse (Mauné et al., 2006), Saint-Romain-de-Jalionas, Isère (Royet, 2006), La Calade du Castellet (Fontvieille) (Amouric et al., 2000), Les Matres-de-Veyre (Romeuf, 1978), Ceyras, Gannes, Les Laurons aux Arcs, Lyon-Vaise, Mesclans à La Crau, Saint-Doulchard, y posiblemente en Marsella, Ambert y Lattes (Brun y Borréani, 1998: 312-317). La villa de Mesclans á la Crau parece que se construyó entre finales del siglo । d.C. y comienzos del II d.C. Las excavaciones han mostrado el conjunto de instalaciones situadas en las inmediaciones: un molino de aceite, almacén, una galería que conectaba las piezas de la vivienda... La mayor parte de los edificios se ordenan formando un conjunto rectangular de 38 por 70 metros. Constituyen la pars rustica de una villa dedicada a la producción de vino, aceite y cereales. Al contrario que la fábrica de Berbegal, acaso explotada por una administración civil, el molino de Mesclans se inscribe en el ámbito particular y doméstico; habría estado destinado a fabricar la harina para la población de una villa, y acaso ocasionalmente a alimentar los circuitos comerciales próximos. El de Les Laurons aux Arcs-sur-Argents, también dependería de una villa: en el centro de un territorio de seis kilómetros por cuatro, el dominio de un rico propietario combinaba sobre más de seis hectáreas su residencia y una gran granja, con un molino hidráulico datados en los siglos III y IV d.C (Brun y Borréani, 1998).

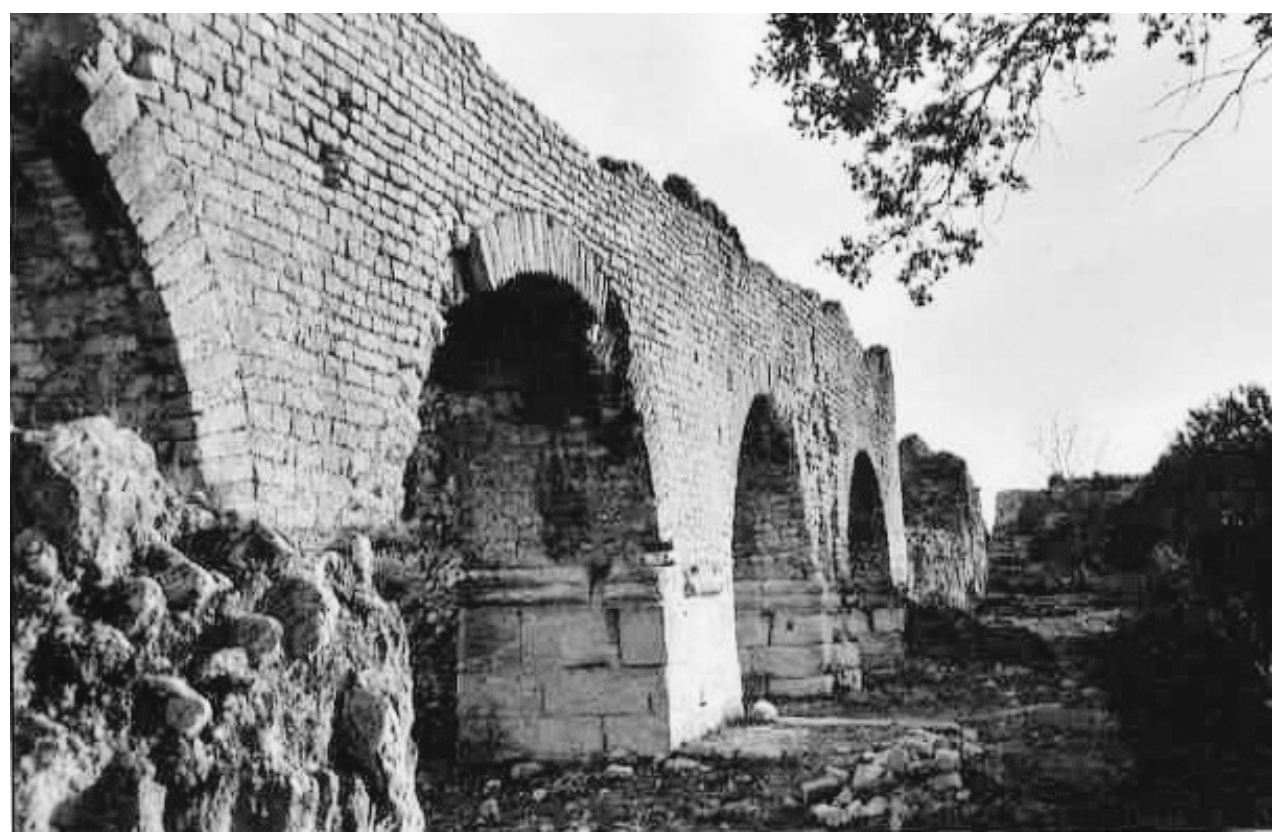

(Según Belmont, 2006.)

Fig. 4. Acueducto del complejo de molinos de Barbegal (Arles, Francia). 


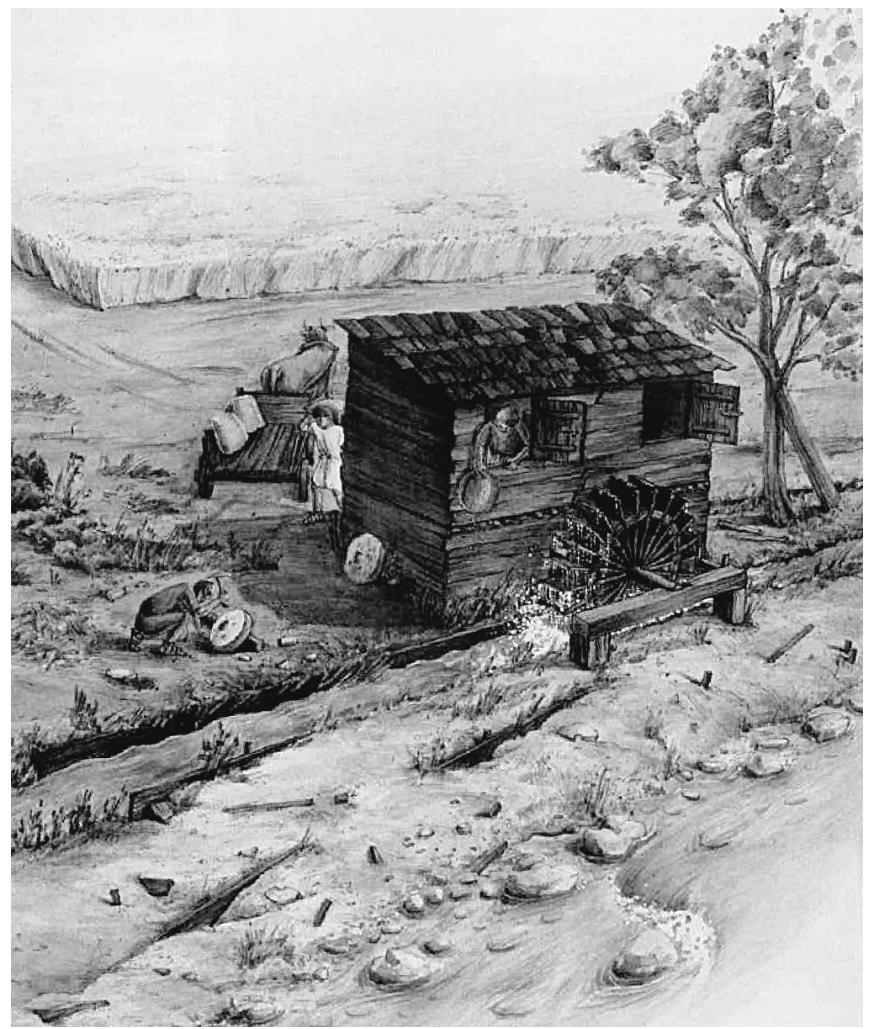

(Según Castella, 1994.)

Fig. 5. Reconstrucción del molino hidráulico de Aventicum, 57-58 d.C. (Avenches, Suiza).

Cerca de la capital de la antigua Helvetia, Aventicum (la actual Avenches) ha aparecido un molino construido en madera (Fig. 5), al que la buena conservación de su estructura ha permitido datarlo por dendrocronología a mediados del siglo I d.C. El análisis químico efectuado sobre las piedras de las muelas apunta como lugar de extracción al «Massif central français. Ces objets très lourds et encombrants faisaient donc l'objet d'un commerce à longe distance» (Castella, 1994) ${ }^{31}$. En la Europa central se conservan más ejemplos en Lösnich (Neyses, 1983), Hagendorn (Gähwiler y Speck, 1991), Dasing en Baviera (Czysz 1994) y München-Perlach (Volpert, 1997).

Se conocen numerosas evidencias de molinos hidráulicos en Inglaterra, como en Ardleigh, Fullerton, Nettleton (Spain, 1984a), Chester Bridge, Haltwhistle Burn Head (Simpson, 1976) e Ickham (Spain, 1984b).

${ }^{31}$ En junio de 2007 se dio a conocer el hallazgo de otro molino muy cercano al de Avenches: http://www.avenches.ch/aventicum/fr/documents/nespresso.pdf. 
La Península Ibérica es un caso paradójico. «Resultaría verdaderamente extraño que una de las partes económicamente más avanzadas del Imperio romano fuera casi la única, excepto las más áridas del norte de África, en no adoptar la energía hidráulica" (Wikander, 1985: 158). La ausencia podría explicarse por la reutilización y modificación que hace que se conserven pocos restos de molinos la época; y porque en España y Portugal la investigación arqueológica no está en este campo a la misma altura que en Inglaterra, Francia o la Europa Central (donde, precisamente, han aparecido más molinos en excavaciones). Las referencias literarias como en el Fuero Juzgo, empero, indican que los molinos de agua no fueron desconocidos para los visigodos. Apenas si hay citada alguna cita procedente de la Península Ibérica, como una rueda hidráulica en Conímbriga (Brun y Borréani, 1998: 309).

Es muy probable que en Augusta Emerita se construyeran molinos al albur de las presas de abastecimiento a la ciudad: «en Proserpina hay a pie de presa un molino, considerado de origen romano, que pudo explotarse perfectamente a partir de una pequeña derivación desde el canal que llevaba las aguas a Mérida" (Arenilla, 2002).

En la orilla izquierda del río Guadarrama se conserva un sistema hidráulico con un conjunto de presas y molinos de cubo que formaron parte del sistema hidráulico de la Villa de Materno (Carranque, Toledo), al otro lado del río. «El que el más antiguo de los molinos, el llamado cubo A, esté hecho de ladrillos de 29,6 x $20 \mathrm{~cm}$, es ya un indicio de su romanidad, puesto que $29,6 \mathrm{~cm}$ son el pie romano, pero los autores del artículo no se atreven de momento a dar una cronología” (FernándezGaliano, 2001: 845). Es muy posible que las reservas provengan de la tradicional consideración de los molinos de agua como eminentemente medievales, pues quizá por el mismo prejuicio han sido datados entre los siglos VII y Xv². Sin embargo, puede observarse un cubo circular en opus lateritium del más puro estilo romano formado por ladrillos con módulo de un pie romano; tanto la villa de Materno como la Basílica cercana son de finales del siglo Iv, d.C.: recordemos la recomendación de Paladio de instalar molinos hidráulicos en aquellas villae que tuviesen suficientes recursos hídricos, por lo que no debe descartarse en principio que este complejo de molinos hidráulicos datase de la segunda mitad del siglo iv d.C.

Durante el estudio sobre la minería romana en Córdoba, en el noreste de la provincia se han encontrado tres ruedas de molino hidráulico, probablemente asociadas a explotaciones mineras romanas. Dos de ellas se encuentran en Belmez (Córdoba), una en el Museo Histórico local y otra en un domicilio particular (García, 2002: 365-363); la tercera se halla en la mina de La Solana (Belalcázar, Córdoba), donde aparecen en superficie numerosos fragmentos cerámicos de finales de la República y Alto Imperio (García, 2002: 140-141 y 364). En el mismo contexto minero Harrison informa de la existencia en las paredes de las casas cercanas a las minas auríferas de Tras os Montes de innumerables secciones de piedras de molino quebradas, similares a las empleadas entonces por los campesinos para moler su trigo en los molinos hidráulicos (Harrison, 1931: 140; citado en García, 2002).

\footnotetext{
32 http://www.dearqueologia.com/carranque_intro.htm.
} 


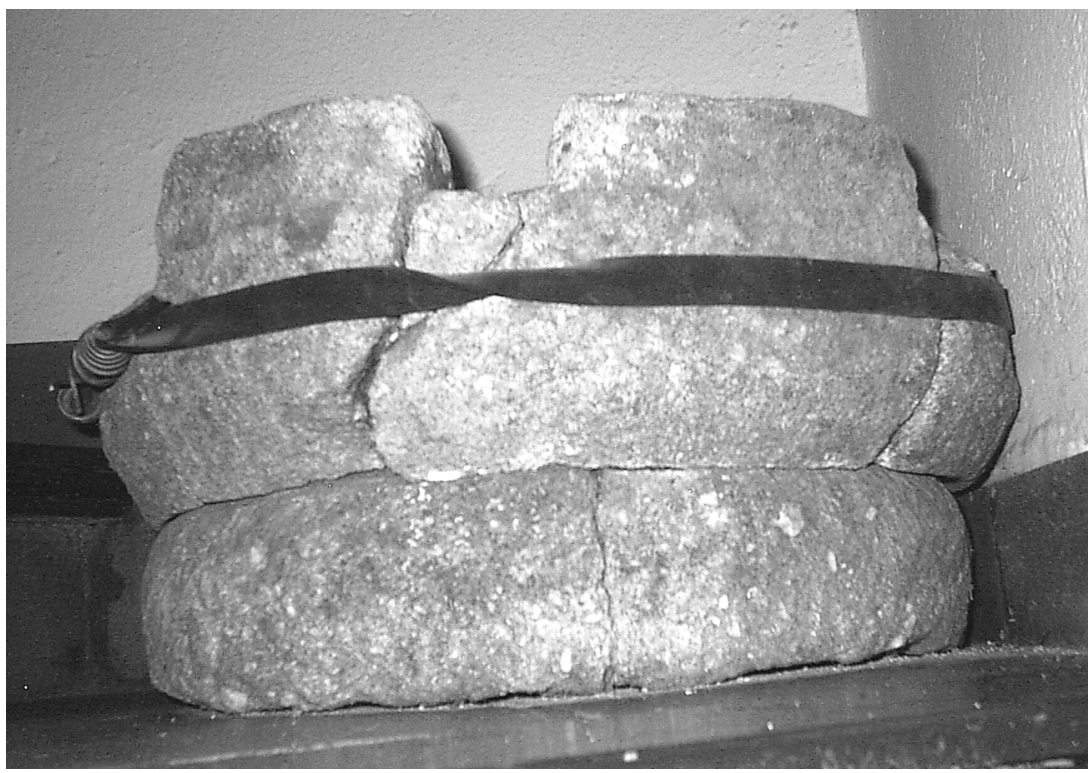

Fig. 6. Piedra de molino hidráulico romano de Azuel, Córdoba, vista lateral.

A estas tres ruedas de molino hidráulico pueden unirse otras dos que damos a conocer que también proceden del norte de Córdoba, aunque en la parte oriental:

Al realizar unas labores agrarias en el paraje de El Endrinal (Azuel, Córdoba) se encontraron a casi un metro bajo tierras dos piedras de molino depositadas en el Museo Histórico de Villanueva de Córdoba, elaboradas en roca granítica local ${ }^{33}$. Una, de $50 \mathrm{~cm}$ de diámetro y $18 \mathrm{~cm}$ de grosor, tiene la entalladura donde se alojó la lavija, lo que demuestra que fue la piedra volandera. Junto a la piedra de molino apareció el eje, formado por un cilindro macizo de plomo, y varias monedas, una de ellas un as de Trajano.

Ninguno de los arroyos cercanos cuenta con un caudal suficiente para garantizar el aporte hídrico regular necesario; sí existe a unos 500 metros aguas arriba un manantial que provee a la finca unos tres mil litros por hora en verano para el abastecimiento del ganado, y que se encuentra a una cota superior en treinta metros a la del molino, lo que confiere el desnivel suficiente para su conducción. Superficialmente, donde aparecieron las piedras de molino no se observan más restos cerámicos que tégulas, algunas de ellas en barro blanco, no local, y de buena factura. También hay otros elementos alóctonos como placas de pizarra, empleadas presumiblemente como pavimento.

${ }^{33}$ Agradecemos la información a don Emilio Jurado Ruiz, que presumiendo que podrían ser piezas de interés, y pese al considerable peso, las trasladó y depositó para su conservación en el Museo Histórico de Villanueva de Córdoba. 


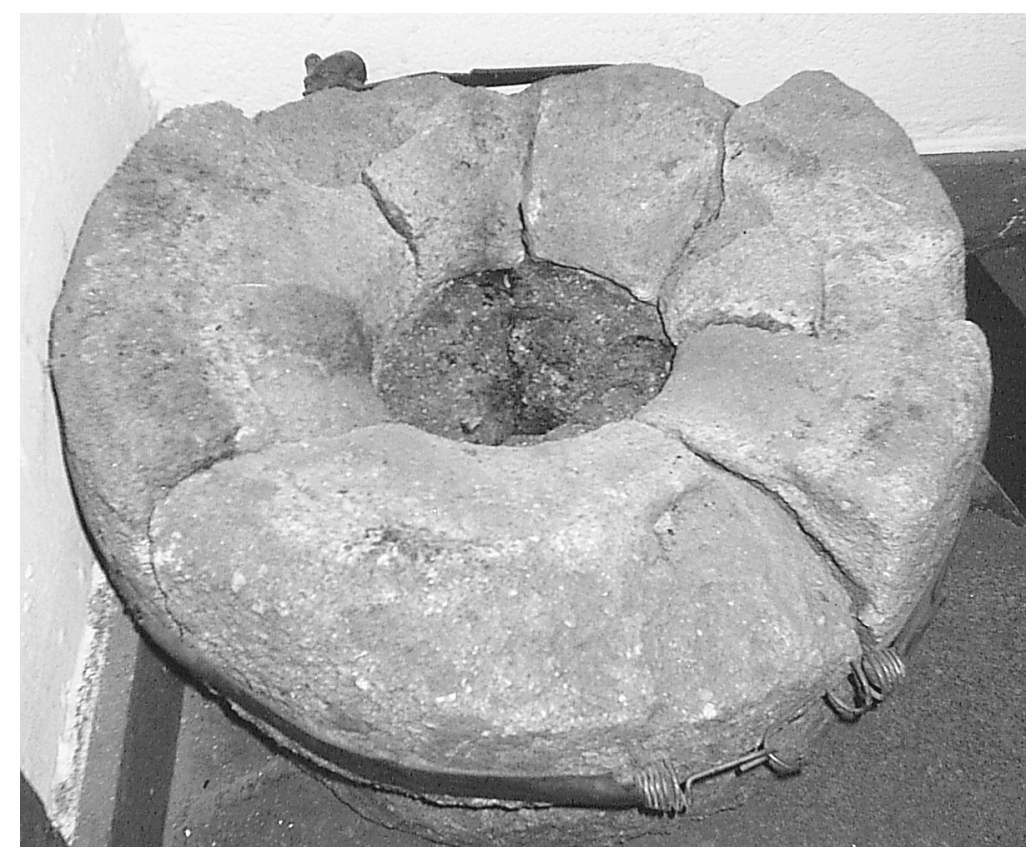

Fig. 7. Piedra de molino hidráulico romano de Azuel, Córdoba, entalladura de la lavija.

Apenas si hay algún estudio sobre la Antigüedad en el norte de Córdoba, pero podemos aventurarnos a elaborar alguna hipótesis que explique la presencia del molino. No se conoce en la zona ninguna ciudad, vicus, villae, lugar de hábitat de cierta entidad o explotación minera de importancia al que asociar el molino. Se encuentra a 4,5 km del conocido como Castillo de Azuel: en sus inmediaciones la reja del arado hizo aflorar en el siglo XIX junto a varias sepulturas un conjunto monetario de denarios romanos republicanos e ibéricos y joyas de plata (Gómez, 1949). El Castillo de Azuel se encuentra a 750 metros de un antiguo «Camino de la Plata», una vía romana que era el camino natural de salida de las ricas explotaciones mineras del sur de la actual provincia de Ciudad Real y del NE de Córdoba hasta la ciudad de Epora (Montoro, Córdoba), donde conectaría con la Vía Augusta (Palomo, 2003). Como decíamos, no se ha hecho ninguna intervención arqueológica en la zona que permita conocer su pasado en el periodo romano, pero no resulta descabellado presumir la existencia en esa fortificación de una vexillatio, de un destacamento militar con el objetivo del control territorial y del tránsito de mercancías y minerales ${ }^{34}$. Tanto soldados como mineros constituyen una clientela

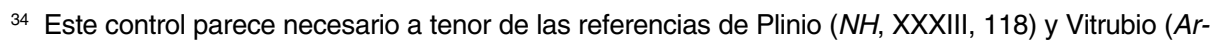
quitectura, VII 9,4) sobre el transporte del minio, que partía de Sisapo (La Bienvenida, Almodóvar del Campo, Ciudad Real), cercana a este camino. Su comercio estaba muy controlado por el estado romano: no era refinado in situ, sino que el mineral en bruto era sellado y transportado a Roma, donde había talleres especializados en su tratamiento. 
potencial para los molinos hidráulicos. Su instalación a una hora andando del Castillo de Azuel estaría determinada por la existencia de un manantial que aportase el caudal de agua imprescindible para la molienda. En cuanto a su datación, los escasos elementos con los que contamos (tégulas de importación; eje de plomo; pavimento con láminas de pizarra de importación; monedas de Trajano) apuntan a su empleo durante el tiempo de una economía sólida, a comienzos del siglo II d.C. (apoya esta hipótesis la ausencia de cualquier otro resto cultural de ninguna otra época).

En la misma zona del NE de la provincia de Córdoba, en el patín de un cortijo del pago de El Rosalejo (4,5 km al norte de Villanueva de Córdoba) se encuentra una rueda de molino, con la característica talla a lo largo de su eje para alojar la lavija, lo que nos indica que perteneció a un molino de agua. Está labrada en roca volcánica no local (acaso procedente del Campo de Calatrava, Ciudad Real, unos cien kilómetros al norte), con $34 \mathrm{~cm}$ de diámetro y $8 \mathrm{~cm}$ de grosor. El orificio para el eje tiene $11 \mathrm{~cm}$ y el ancho de la entallatura para la lavija es de $5,5 \mathrm{~cm}$. Conserva aún restos de plomo de la lavija.

Lo guardeses actuales de la finca nos informan de que puede llevar allí más de cuarenta años, pues salió cuando aún se araba con yuntas de mulos, y alguien decidió emplearla como objeto decorativo en lugar de material de construcción (como el ara a Marte que citamos después).

Tras indicarnos dónde parece ser que apareció, nos desplazamos al lugar. Está a algo más un centenar de metros del arroyo del Molinillo, aunque no en la zona aluvial del mismo. En el lugar, como en el caso anterior del molino de Azuel, se observan en la superficie fragmentos de láminas de piedra de pizarra (alóctona por completo en el batolito granodiorítico de los Pedroches) y numerosísimos restos cerámicos, siendo los más característicos bordes de tégulas y ladrillos de pequeño tamaño; el barro de las tégulas es de color rojo y anaranjado, con pasta bien depurada, sin apenas desgrasantes y con una buena cocción; el extremo de las tégulas hace un pequeño rebaje biselado. No se aprecian vestigios de ningún canal para conducir agua ni hiladas de cimentaciones $u$ otros vestigios de construcción, el edificio u obra humana más cercana que se encontraba a unos doscientos metros eran unas zahúrdas, en cuyo interior se amortizó una inscripción a domino Marti en roca granítica local recogida por Stylow ${ }^{35}$, de finales del siglo I d.C. o inicios del II d.C. Hay también restos de cerámica común aunque sin formas ni bordes definidos; debe destacarse que no se observa ningún fragmento de barro de elementos característicos del periodo hispanomusulmán (tejas árabes, cerámicas vidriadas o con engobe y decoración en verde y manganeso, ataifores o jofainas, lucernas de piqueras con vedrío...) o posteriores.

Dado el modo del descubrimiento, una adscripción temporal completamente segura de esta rueda de molino no resulta factible por completo, pero hay que apuntar que el sustrato edáfico del lugar corresponde al del batolito granítico de los

35 (-) Porciu(s) / (-c.2) Fron(to) / (d)omino / (M)arti • a(ni) / mo libe(ns) / ------. (Stylow, 1986, 266). 
Pedroches, con un suelo con perfil tipo $A(B) C$, y un horizonte $A^{36}$ de muy escasa potencia dado la resistencia de estas rocas a la meteorización. Si este molino correspondiese a una etapa posterior a la romana y hubiese habido una superposición de los estratos de cada época, del mismo modo que las muy superficiales labores del arado sacaron a la luz tégulas e ímbrices, podrían haberlo hecho con esos posibles materiales, en caso de haber existido. Sin una excavación en condiciones no se pueden hacer afirmaciones categóricas, pero no parece ilícito relacionar esta piedra de molino con la época de las cerámicas que se pueden reconocer in situ (periodo romano, en general, sin poder hacer más precisiones), más que con las de un periodo posterior del que no existe el menor tipo de vestigio.

A un par de kilómetros aguas arriba del arroyo del Molinillo sí se aprecian represas y canales para el uso de molinos de agua; pero en este caso en las inmediaciones hay varios restos de hábitat (según parece por las cimentaciones visibles), que tienen unos las características tégulas y otros fragmentos de cerámicas con vedrío melado y líneas negras de manganeso, propias del periodo hispanomusulmán. Aquí no es factible simplemente con la observación de la superficie poder encuadrar esas obras de los molinos a un periodo concreto, pero en la piedra de molino volcánica que tratamos no tenemos esa disyuntiva, todos los elementos reconocibles pertenecen al periodo romano.

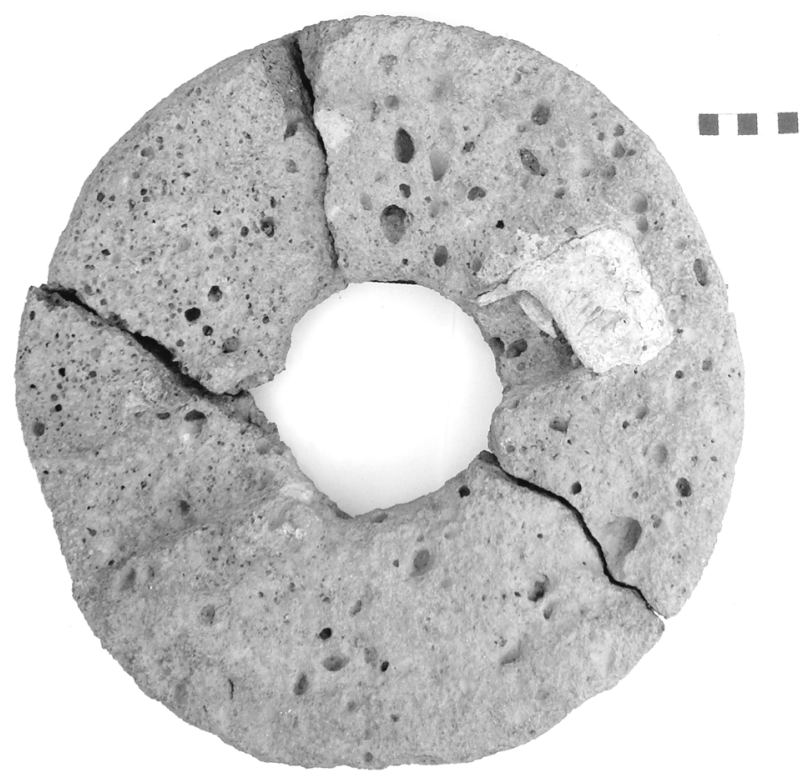

Fig. 8. Piedra de molino hidráulico de El Rosalejo (Villanueva de Córdoba).

36 «En el horizonte $A$, siempre suelto y de textura arenosa, se reconoce un subhorizonte $A_{1}$, de unos cinco centímetros de espesor... el subhorizonte $A_{2}$ [es] algo más potente...» (Valle, 1984, 81). Consecuentemente, el regolito que cubre la roca madre está a escasa profundidad de la superficie. 


\section{LOS MOLINOS HIDRÁULICOS EN LA ANTIGÜEDAD}

La cuestión de la invención del molino hidráulico ha suscitado opiniones y orígenes controvertidos ${ }^{37}$. Con la premisa de que los molinos hidráulicos tuvieron un origen oriental, desde donde llegaron después a la Europa medieval ${ }^{38}$, China fue uno de los lugares propuestos, pero no hay pruebas ciertas del uso de molinos harineros en ese país anteriores al siglo v d.C. (Wikander, 2000: 394).

Durante mucho tiempo se dio más o menos por sentado que el modelo más simple de molino de rueda horizontal precedió al técnicamente más avanzado de rueda vertical, aunque por el momento no conocemos molinos de ruedas horizontales hasta fines del siglo III d. C - los más antiguos conocidos son los de turbina de Chemtou y Testour, que en absoluto pueden ser descritos como simples-. En la búsqueda del origen de la molienda por la acción hidráulica más bien debería estudiarse el molino de rueda vertical cuya construcción depende de la existencia de piedras de molino rotatorias, del engranaje perpendicular y ruedas hidráulicas que lo accionen. El conocimiento sobre los mecanismos y engranajes antiguos ha mejorado durante las últimas décadas, y a tenor de lo que hoy conocemos las ruedas dentadas que se unen perpendicularmente estaban en uso una o dos décadas antes de la mitad del III a.C.; con ello se permitía cambiar el sentido de la fuerza motriz noventa grados, aplicando a la par un desarrollo diferente al del eje de giro de la rueda. Las ruedas elevadoras de agua no pueden ser datadas con precisión, pero fueron aparentemente usadas en Egipto a comienzos del siglo III a.C. Una fecha alrededor del 270-260 a.C. parece ser el terminus post quem para la invención del molino hidráulico (Wikander, 2000: 395). Muy poco después de ese tiempo es la fecha propuesta por Lewis para su invención. Analizando varios tratados tecnológicos helenísticos, como una sección de la Pneumatica de Filón de Bizancio que se consideraba una interpolación árabe posterior ${ }^{39}$, ofrece argumentos para asignar la invención del molino de rueda vertical en Alejandría en el 240 a.C., y el de rueda horizontal en Bizancio algo más temprano, pero tal vez sólo algo antes de ese tiempo (Lewis, 1997: 33-61). Las citas de Estrabón, Antipater y Vitrubio son más o menos contemporáneas, de época de Augusto, y preceden a todos los hallazgos arqueológicos que se conocen, por lo que se convierten en el término

37 «La historia más antigua de la energía hidráulica es un área de investigación donde nuestra lamentable carencia de auténticas evidencias ha animado la negligencia, la lectura descuidada de las fuentes literarias, y conjeturas fantásticas basadas sobre paralelos superficiales con el desarrollo de la energía hidráulica en el imperio chino Han, y un presunto molino del siglo I a.C. de rueda horizontal en Bolle, Dinamarca (!)... La datación de Bolle parece estar bien fundada, su identificación con un molino de agua mucho menos. El excavador argumentó con fuerza su interpretación como un molino de rueda horizontal, pero hoy pocos eruditos estarían de acuerdo» (Wikander, 2000: 394-395).

38 «Ciertamente el molino fue un elemento importante en el mundo asiático, desde China a Siria, mucho antes de la Edad Media [europea]» (Le Goff, 2005: 107).

39 El argumento para considerar que la mención a molinos de agua en el texto de Filón son intrusiones árabes muy posteriores no ofrecía ninguna razón mejor que el mundo antiguo no fue capaz de pensar tales invenciones en aquellas épocas, lo que no deja de ser un razonamiento tautológico. Según Lewis, las secuencias de letras que numeran los detalles de las ilustraciones de las obras de Filón muestran que los capítulos relevantes son traducciones del griego y no interpolaciones árabes (Lewis, 1997: 26-36). 
ante quem, aproximadamente entre el 25 a.C. y el nacimiento de Cristo (Wikander, 2000: 395).

Es probable que el molino de agua naciese en el Mediterráneo oriental ${ }^{40}$, hacia mediados del siglo III a.C., aunque la difusión en el mundo helenístico del molino accionado hidráulicamente pudo ser más lenta que en el Mare Nostrum romano, donde la uniformidad económica y cultural habría supuesto la "masa crítica» (Wilson, 2002: 11) que asegurase su rápida expansión. Al examinar P. Roos el texto de Estrabón (Geografía, XII, 3, 30) considera que el molino del palacio Cabeira que encontraron los legionarios de Pompeyo formaba parte de un conjunto que no parecía ser una novedad para el geógrafo griego, se limita a citarlo, sin añadir ninguna descripción o comentario. Considera este autor que Lucullus, responsable de la introducción en Roma de otras novedades como la cereza, habría podido trasladar a Italia la técnica del molino hidráulico (Roos, 1996). Las dataciones por dendrocronología demuestran la expansión del molino de agua a comienzos del Imperio al menos por lugares periféricos del mismo, Helvetia y Germania: el molino de Avenches es del 57-58 d.C., y de 102-112 d.C. el molino rural cerca de Dasing en Baviera. En la Galia el primero de los dos molinos de Martres-de-Veyre fue edificado en el siglo I d.C.; la construcción de Barbegal se remonta a inicios de la segunda década el siglo ॥l.C.

Uno de los factores que determina el uso del molino hidráulico es su rentabilidad, y para considerar la eficiencia económica de un proceso productivo se deben tener en cuenta los gastos de inversión y costes de producción. En teoría, la instalación del molino de agua necesitaría:

- Organización estatal, capaz de acometer las obras necesarias de construcción y mantenimiento; o de garantizar la paz y el orden social que permitieran a los particulares emprender y rentabilizar la obra.

- Rentabilidad económica garantizada; en este caso núcleos de población cercanos y de gran tamaño, cuya demanda asegure el consumo de la producción. Es interesante la observación de que varios molinos hidráulicos que se han encontrado en Gran Bretaña estén junto al Muro de Adriano (Spain, 1984); o las piedras de molino encontradas en contextos mineros de Córdoba o en el NW peninsular. El ejército y los grupos de mineros forman parte de esa demanda natural, un gran número de personas con una actividad determinada (el control del territorio o las labores extractivas) al que no le interesa desperdiciar energía en la obtención del pan nuestro de cada día con el laborioso método de los molinos de mano.

- Ratio de resultado de la producción/costes de construcción, mantenimiento y producción positivo, y en un tiempo óptimo. El coste total del producto

40 Las referencias más antiguas de Estrabón o Antipater (e incluso Filón de Bizancio) proceden de esa zona. Vitrubio parece que no conocía una palabra latina para definir el molino de agua. Se admite que el término hydraletae en su texto es una corrección moderna, pero en los manuscritos se lee hydraulae o ydraulae, lo que demuestra fuera de toda duda que Vitrubio empleó una palabra griega (Wikander, 2000: 396). 
obtenido dependerá del periodo de amortización de la instalación (toda la infraestructura necesaria, canales y acueductos de conducción del agua, engranajes metálicos, ruedas y paletas..., supondría una gran inversión inicial); del coste de mantenimiento de la instalación como tal, y del coste de producción del producto final obtenido.

El cumplimiento o no en mayor o menor grado de los tres asertos anteriores podría explicar la existencia de molinos y sus lugares de ubicación, así como su mayor o menor presencia según las distintas épocas. En principio, estas instalaciones técnicas y costosas necesitarían de una organización estatal fuerte que avalase su rentabilidad en el tiempo, y de grandes núcleos de población que garantizasen la demanda y la producción. Circunstancias que se dan a comienzos del siglo II d. C, cuando Berbegal está en plena actividad; pero que cambian radicalmente siglos después, lo que propiciaría una recesión en la expansión del uso de molinos hidráulicos: esto parece desprenderse al comprobar el mayor número de molinos conocidos por la Arqueología de los siglos II d.C. y III d.C. respecto a los de los tres siglos posteriores (Fig. 2).

El ejército romano podría haber actuado como vector de propagación de la tecnología hidráulica en las provincias, pero se conocen también gran número de molinos en contextos civiles, urbanos y rurales, por todas partes del Imperio. Los molinos de agua abastecían desde el Janículo o las Termas de Caracalla a la población romana (que, según Procopio, sufrió la carestía de pan cuando dejaron de funcionar en el asedio godo del 537); asimismo, dentro de un ámbito urbano de gran población pueden entenderse los complejos de Barbegal para Arles o Cesárea Marítima. No se tiene claro quiénes eran los responsables de la construcción y uso de esos grandes "complejos industriales", si individuos privados o dependientes de la municipalidad, pero suponen una considerable inversión inicial y están diseñados claramente para producir una gran cantidad de harina. Se ha argumentado que la construcción de algunos podría estar en relación con la annona aunque no hay demasiada información que aporte datos inequívocos en este aspecto (Wilson, 2002: 13-15). Los molinos hidráulicos surtieron también a pequeñas ciudades como Saepinum, donde un molino era impulsado por la red del acueducto de la ciudad.

La antigua Galia es una de las provincias donde más excavaciones y descubrimientos de molinos de agua se han realizado en el mundo rural. La mayoría de las instalaciones corresponden al Alto Imperio, coincidiendo con el movimiento de inversión agrícola durante los Flavios y la primera mitad del siglo II d.C. Las villae son a menudo lujosas, dotadas de columnatas, termas..., agradables para la residencia del propietario. Es normal que en éstas se economizase mano de obra servil mediante prensas o molinos hidráulicos. En algunos casos la modestia de las instalaciones hace pensar en un destino doméstico para abastecimiento del dueño y de su familia; pero en otros, como Les Mesclans, es lícito imaginar que un molino de su entidad, más allá de las necesidades domésticas, trabajara también para propiedades vecinas e incluso para los panaderos de alguna población próxima. Lejos del bloqueo tecnológico se asiste a una difusión y trivialización de la tecnología que permite economizar la fuerza de trabajo, incluso en el mundo rural. 
Muchas de las pequeñas granjas galas comenzaron a abandonarse a finales del siglo II y primera mitad del III d.C.; en las grandes a partir de esa fecha se abandonan las instalaciones de producción pero no de los complejos residenciales, lo que sucede a final de ese siglo y comienzos del IV d.C. (Brun y Borréani, 1998: 317-318). Los molinos de agua se desatienden a la par que las villae, lo que parece indicar que su mayor o menor empleo en tan cortos periodos de tiempo también depende de los factores estructurales, sociales y económicos de cada momento, y no sólo de los conocimientos teóricos o técnicos.

"Actualmente, más que una brusca floración de molinos hidráulicos impulsados por el feudalismo entre los siglos x y xII, surge la convicción de una expansión casi lineal desde la Antigüedad. Las crisis económicas del Bajo Imperio después de los desórdenes nacidos de las grandes invasiones, debieron frenar un tiempo este gran movimiento de fondo" (Belmont, 2006: 23). Tampoco el progreso y el crecimiento siguen necesariamente un modelo lineal de avance, las tecnologías se olvidan y se adoptan ${ }^{41}$.

\section{CONCLUSIONES}

«Durante la Antigüedad tardía... cada día se documentan más testimonios del empleo de molinos hidráulicos, cuya aparición en Occidente se había creído hasta hace poco que tenía su origen en la Edad Media. Tales molinos suponían una importante liberación de las energías humanas y animales que habían exigido los molinos antiguos» (Mangas, 2003: 488-489). Y también en el periodo anterior, «hoy, nadie discute la realidad de los molinos de agua en el Imperio romano. Al contrario, los descubrimientos se multiplican y vienen a confirmar la amplitud de su expansión en el curso de los primeros siglos de nuestra era” (Belmont, 2006: 20).

Parece ser que los romanos combinaron diferentes modos de molienda con arreglo a la necesidad de la población a abastecer: los molinos en mano habrían sido utilizados en el marco doméstico y rural; los molinos de sangre en fábricas de harinas artesanales urbanas; los pequeños molinos hidráulicos en las villae y en vici cerca de los campos militares o en pequeñas poblaciones; y las factorías de molinos en el abastecimiento de las grandes ciudades (Belmont, 2006: 23). Nuevos descubrimientos sobre su uso en la Antigüedad, especialmente desde la Arqueología, han variado el estereotipo que se tenía sobre su falta de empleo en esta época. A tenor de lo que hoy conocemos, los molinos hidráulicos no fueron una curiosidad de los ingenieros romanos, sino que se emplearon profusamente al menos desde el siglo I d.C.; no surgen como consecuencia de la desaparición de la esclavitud entre los siglos v y XI d.C., los había funcionando en Barbegal en plan industrial cuando el Imperio estaba en pleno vigor y auge con Trajano ${ }^{42}$; y no nece-

41 «Growth and progress do not necessarily follow a linear pattern and advance; technologies are lost as well as adopted» (Wilson, 2002: 1).

42 A los siglos II d.C. y III d.C. pertenecen el mayor número de molinos hidráulicos conocidos por la Arqueología. 
sitaron ser traídos a Europa por los musulmanes ni esperar a la época de las cruzadas, pues acaso los griegos del periodo helenístico primero, y romanos, bizantinos, merovingios o visigodos después los usaron.

El origen de los molinos de agua medievales europeos está, precisamente, en el germen de la propia historia de Europa, en el Imperio romano que los conoció en el mundo helenístico y los difundió desde Asia Menor a la Galia, Germania o Britania. Si a los molinos de agua se les reconoce cierta importancia para la economía medieval, las pruebas de las que disponemos sugieren que también lo fueron para el mundo romano (Wilson, 2002: 15). Queda seguir excavando e investigando para conocer su relevancia en cada época y región.

\section{BIBLIOGRAFÍA}

AMOURIC, H. et al. (2000): «Un moulin à turbine de la fin de l'Antiquité, - La Calade du Castellet (Fontvieille)», P. Leveau and J.-P. Saquet (eds), Milieu et sociétés dans la vallée des Baux. Études présentées au colloque de Mouriès. Revue Archéologique de la Narbonnaise, supplément 31, pp. 261-73, Montpellier, Éditions de l'Association de la Revue Archéologique de Narbonnaise.

ARENILLA, M. (2002): «Obras hidráulicas en Hispania«, I Congreso de Obras Públicas romanas Mérida 15/11/2002, http://traianus.rediris.es/textos/hidraulicas.htm.

BELMONT, A. (2006): La Pierre à pain. Les carrières de meules de moulins en France du Moyen Âge à la révolution industrielle, Tomo 1, Grenoble, Presses Universitaires de Grenoble.

BENOIT, F. (1940): «L'usine de meunerie gallo-romaine de Barbegal (Arles)», Revue Archéologique 15, pp. 19-80.

BLOCH, M. (1935): «Avénement et conquête du moulin à eau«. Annales d'histoire économique et social N. ${ }^{\circ} \mathrm{VII}$, pp. 538-563.

BRUN, J.-P., BORRÉANI, M. (1998) «Deux moulins hydrauliques du Haut-Empire romain en Narbonnaise: villae des Mesclans à La Crau et de Saint-Pierre/Les Laurons aux Arcs (Var)», Gallia 55, págs. 279-326.

BUCKLER, W. y ROBINSON, D. (1932), Sardis, VII, Greek and Latin Inscriptions, Leiden Publications of the American Society for the Excavation of Sardis.

BUFFAT, L. (2006): «Moulin d'époque romaine à la Croix de Fenouillé (Castillon-du-Gard, 30)", Colloque International Le Pont du Gard 20-22 septembre 2006, Force hydraulique et machines à eau dans l'Antiquité romaine, http://f.echasseriaud.free.fr/pages/actu/ actu04a.ill/actu0406/pontgard.pdf.

CASTELLA, D. (1994): Le moulin hydraulique gallo-romain d'Avenches "en Chaplix", Lausanne, Cahiers d'archéologie romande 62.

CHASTAGNOL, A. (1981): «L'inscription constantinienne d'Orcistus «, Melanges de l'Ecole française de Rome, Antiquité 93, pp. 381-416.

CZYSZ, W. (1994) «Eine bajuwarische Wassermühle im Paartal bei Dasing», Antike Welt 25, pp. $152-4$.

FERNÁNDEZ-GALIANO, C., et al. (2001): «Carranque. Centro de la Hispania romana. Museo Arqueológico Regional, Alcalá de Henares, 27 Abril- 23 Septiembre 2001, Madrid, Museo Arqueológico Regional, 2001 », Gerion 19, pp. 844-848.

FONDATION ET ASSOCIATION PRO AVENTICO (2007): http://www.avenches.ch /aventicum/fr/documents/nespresso.pdf

GÄHWILER, A. y SPECK, J. (1991): «Die römische Wassermühle von Hagendorn bei Cham ZG», Helvetia Archaeologica 86, pp. 34-75. 
GARCÍA, J. (2002): Minería y metalurgia en la Córdoba romana, Córdoba, Servicio de Publicaciones de la Universidad de Córdoba.

GÓMEZ MORENO, M. (1949), «El Tesorillo de Azuel», Misceláneas; Historia, Arte, Arqueología. Primera Serie: La Antigüedad, Madrid, CSIC, pp. 343-346.

GOUNAROPOULOU, L. y HATZOPOULOS, M.B. (1998): Epigraphes Katô Makedonias i. Epigraphes Beroias, Atenas.

HARRISON, F. (1931): «Ancient Mining Activities in Portugal», Min.Mag. 45, pp. 137-145.

JACONO, L. (1938): «La routa idraulica di Venafro», L'ingegnere 12-15, pp. 850-853.

LE GOFF, J. (2005): «La revolución del molino», La Aventura de la Historia 84, 10-2005, pp. 102-107.

LEVEAU, P. (1996) « Les moulins de Barbegal dans leur environnement. Archéologie et histoire économique de l'Antiquité «, Histoire et sociétés rurales 6, $2 .{ }^{\circ}$ semestre 1996, pp. 11-29.

LEVEAU, P. (2006): «Les moulins de Barbegal (1986-2006)», http://traianus.rediris.es/textos/ barbegal.pdf

LEWIS, M. (1997): Millstone and Hammer: the origins of water power, Hull, University of Hull Press.

MANGAS, J. (2003): Historia Universal. Edad Antigua. Roma, Barcelona, Editorial Vicens Vives.

MANZANO MORENO, E. (2006): Conquistadores, emires y califas, Barcelona, Crítica.

MAUNÉ, S. et al. (2006): "Puits, conduites, aqueduc et moulin. Maîtrise et utilisation de l'hydraulique dans l'établissement de l'Auribelle-Basse (I-Ille s. ap. J.-C.; Pézanas, Hérault)", Colloque International Le Pont du Gard, Force hydraulique et machines à eau dans l'Antiquité romaine, http://f.echasseriaud.free.fr/pages/actu/actu04a.ill/actu0406/ pontgard.pdf.

MOURE CASAS, A. (1990), Tratado de Agricultura de Paladio, Madrid, Biblioteca Clásica Gredos.

MUMFORD, L.. (2002-1934): Técnica y civilización, Madrid, Alianza Editorial (v. o. 1934 de Harcourt \& World, Inc). Edición digital en: http://hps.infolink.com.br/peco/mum_c27.htm.

NEYSES, A. (1983): «Die Getreidemühlen beim römischen Land- und Weingut von Lösnich (Kreis Bernkastel-Wittlich)», Trierer Zeitschrift 46, pp. 209-221.

NIETO, M. (1984): Historia de Córdoba. Islam y cristianismo, Córdoba, Publicaciones del Monte de Piedad y Caja de Ahorros de Córdoba.

OLESON, J. P. (1984): «A Roman water-mill on the Crocodilion river near Caesarea», Zeitschrift des Deutschen Palästina-Vereins 100, pp. 137-152

PALOMO, J. (2003) «La red viaria antigua en Los Pedroches orientales», El Miliario Extravagante 87.

PARSONS, A. W. (1936): «A Roman water-mill in the Athenian Agora», Hesperia 5, pp. 70-90.

PLEKET, H. (1988) «Greek Epigraphy and Comparative Ancient History: Two Case Studies», Epigraphica Anatolica 12, pp. 25-37

ROMEUF, A. (1978): “Un moulin à eau gallo-romain aux Martres des Veyre (Puy-deDôme»), Revue d'Auvergne 92, 2, págs. 23-41.

ROOS, P. (1991): «Zu antiken Wassermülhe in Kleinasien», en Basgelen N. y Lugal M. (eds.), Fetschrift für Jale Inan, Estambul, pp. 495-499

ROOS, P. (1996): «Strabo and the water-mill at Cabeira. Some considerations», Opuscula Romana 20, pp.99-103.

ROYET, R. (2006): «Les moulins de la ville du Vernai à Saint-Romain-de-Jolionas (Isère)», Colloque International Le Pont du Gard, Force hydraulique et machines à eau dans l'Antiquité romaine, http://f.echasseriaud.free.fr/pages/actu/actu04a.ill/actu0406/ pontgard.pdf.

SEIGNE, J. (2002): «Une scierie mécanique du Vlè siècle», Archeologia 385, pp. 36-37.

SELLIN, R. (1983): «The large Roman water-mill at Barbegal (France)», History of Technology 8, pp. 100-101.

SIMPSON, Gr., edit. (1976): Water-mills and military works on Hadrian's Wall. Excavations in Northumberland 1907-1913, Kendal, Titus Wilson \& Son. 
SMALL, A. y BUCK, R. (1994): The excavations of San Giovanni di Ruoti -I- The villas and their enviroment, Toronto, R.O.M.

SPAIN, R. J. (1984a): «Romano-british watermills», Archaeologia Cantiana 100, pp. 101-128.

SPAIN, R J. (1984b): «The second century romano-british water-mill at Ickham, Kent», History of Technology 9, pp. 143-180.

STYLOW, A. U. (1986): «Beitrage zur Lateinischen Epigraphik im Norden der Provinz Córdoba I: Solia», Madrider Milleilungen 28.

TROVÒ, R. (1996): «Canalizzazioni lignee e ruota idraulica di età romana ad Oderzo (Treviso)», Quaderni di archeologia del Veneto 12, pp. 119-34.

VALLE, B. (1981): Geografía Agraria de Los Pedroches, Servicio de Publicaciones de la Excma. Diputación Provincial, Córdoba

VOLPERT, H. (1997): «Die römische Wassermühle einer villa rustica in München-Perlach», Bayerische Vorgeschichtsblätter 62, pp. 243-278.

WIKANDER, Ö. (1979): «Water Mills in Ancient Rome», Opuscula romana 12, pp. 13-36.

WIKANDER, Ö. (1984): Exploitation of water-power or technological stagnation? A reappraisal of the productive forces in the Roman Empire, Lund, Studier utgivna av Kungl. Humanistiska Vetenskapssamfundet i Lund.

WIKANDER, Ö. (1985): «Archeological evidence for early water-mills. An interim report», History of Technology 10, págs. 151-179.

WIKANDER, Ö. (2000): «The water-mill», en Ö. Wikander (ed.), Handbook of Ancient Water Technology, Technology and Change in History 2, Leiden, pp. 371-400.

WILSON, A. (1995): «Water-power in North Africa and the development of the horizontal water-wheel», Journal of Roman Archaeology 8, pp. 499-510.

WILSON, A.(2001a): «The water-mills on the Janiculum», Memoirs of the American Academy at Rome 45, pp. 219-246.

WILSON, A. (2001b): «Water-mills at Amida: Ammianus Marcellinus 18.8.11», Classical Querterly 51.1, pp. 231-236.

WILSON, A. (2002): «Machines, power and the ancient economy», Journal of Roman Studies 92, pp. 1-32.

WILSON, A. (2007): «The uptake of mechanical technology in the ancient world: the watermill», Oxford Roman Economy Project, Universidad de Oxford: http://oxrep. class.ox.ac.uk/index.php?option=com_content\&task=view\&id=33\&ltemid=114. 